\title{
THE ROLE OF VENTRAL HERNIA IN THE CORRECTION OF DIAPHRAGMATIC DEFECTS IN THE NEWBORN*
}

\author{
BY \\ IRVING A. MEEKER, JR. and WILLIAM N. KINCANNON \\ From the Department of Surgery, School of Medicine, University of Southern California, \\ the Children's Hospital and the Los Angeles County Hospital, Los Angeles, California, \\ and the Huntington Memorial Hospital, Pasadena, California, U.S.A.
}

A disconcerting rise in mortality following surgical repair of a congenital diaphragmatic hernia in the newborn has been encountered in many centres in recent years and has prompted this study. Paradoxically this rise in surgical mortality has occurred despite greater surgical knowledge and experience in the correction of such diaphragmatic defects. The rise may be attributable to the increasing number of infants with congenital diaphragmatic defects being correctly diagnosed and undergoing surgery within hours after birth (Bonham Carter, Waterston, and Aberdeen, 1962).

This study concerns the value of ventral hernia in the successful surgical management of infants under 24 hours of age undergoing correction of their diaphragmatic defects.

In the past, following surgical correction of a diaphragmatic defect in a newborn infant, regardless of the age of the child, primary closure of all layers of the abdominal wall has been advocated and carried out wherever possible. Primary closure of the abdominal wall increases intra-abdominal tension (Ladd and Gross, 1940) and limits free excursion and movement of the diaphragm, thus perpetuating the impaired respiratory exchange that existed before operation. Increased intra-abdominal tension incident to primary wound closure may compress the inferior vena cava, reducing venous return to the right heart, causing inadequate tissue perfusion, potentiating tissue anoxia and acidosis (lactic acid accumulation) already established, further lowering arterial oxygen saturation and blood $p \mathrm{H}$ to lethal levels.

It was postulated that the increased mortality following surgical repair of diaphragmatic defects in infants under 24 hours of age might well be related to such increases in intra-abdominal tension following

\footnotetext{
* A paper read at a meeting of the British Association of Paediatric Surgeons in Rotterdam, September 1964.
}

primary wound closure, and that the lethal physiological derangements that might ensue could be consistently and effectively combated by arbitrarily employing ventral hernia in such cases.

In addition to our experiences with ventral hernia after closure of a diaphragmatic defect, this report will include current adjunctive therapeutic considerations as regards pre- and post-operative management, with particular emphasis on the value of chest drainage and gastrostomy in such infants.

\section{Clinical Material}

There are 38 consecutive, unselected infants in this study representing-regardless of associated congenital anomalies or other considerations-all cases accurately diagnosed or undergoing surgical repair of their congenital diaphragmatic defects during the first 24 hours of life from 1957 to 1963 at the Children's Hospital of Los Angeles, the Los Angeles County General Hospital, and the Huntington Memorial Hospital of Pasadena. These patients are divided into four main groups. Group I: 11 infants who died en route to the hospital, on admission, or shortly thereafter before an operation could be performed. Group II: 11 infants who had standard correction (Gross, 1953) of a diaphragmatic defect through a divided rectus muscle incision and a skin-covered ventral hernia created. Group III: 6 infants who had standard correction of the diaphragmatic defect through a paramedian incision and creation of ventral hernia with temporary closure. Group IV: 10 infants who had standard correction of the diaphragmatic defect followed by primary closure of all layers of the abdominal incision.

Table 1 documents the pertinent clinical data in the 27 surgical cases in Groups II, III, and IV.

In the 27 infants whose diaphragmatic defects were repaired, the type of abdominal wall closure selected in each instance was determined solely by the practice of the surgical service to which the child was admitted. 

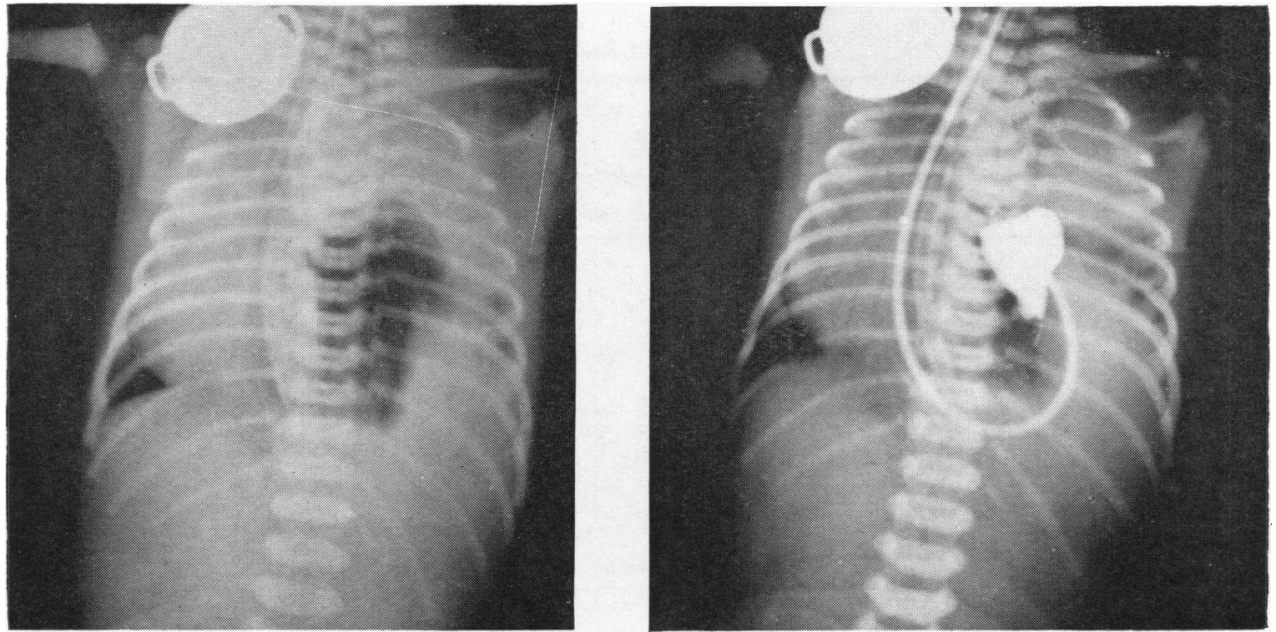

FIG. 1.-Portable radiographs of Case 5 showing the thorax (left) before instillation of 'dionosil oily' into the stomach and (right) 5 minutes after insertion of the oily media into the stomach.

No infant who had a heart beat and was still breathing was denied surgical repair, no matter how desperate the risk or the gravity of apparent central nervous system damage from prolonged anoxia. Of the 27 cases, 26 were full-term infants: the lone premature infant weighed $4 \mathrm{lb} .9 \mathrm{oz} .(2,069 \mathrm{~g}$. $)$.

\section{Pre-operative Management}

The impressively large number of infants dying or moribund during the first day of life and before correction indicates that any delay in diagnosis and surgical intervention may permit natural selection by 'survival of the fittest', and this may well have favourably affected over-all mortality statistics in the past when related to the present. To give as many infants as possible a chance for survival, surgical correction of the diaphragmatic defect must be done as soon as the child can be transported to an area where experienced anaesthetic and surgical personnel are available and appropriate operating facilities can be made ready.

A nasogastric tube is inserted into the stomach as soon as the diagnosis is made to prevent dilatation of the intestinal tract by swallowed air, which causes further compression of the lungs and impairment of pulmonary function. At all times this tube should be on continuous suction-or clamped during transport-to prevent the 'sucking' of large volumes of air into the stomach and intestine in the thorax with each respiratory movement.

If there is difficulty in differentiating a congenital diaphragmatic defect from other conditions affecting the lung and/or causing cyanosis, 5 to $10 \mathrm{ml}$. of 'lipiodol' or 'dionosil oily'* may be instilled through the tube into the stomach. With a diaphragmatic defect the contrast media will appear within 10 to 15 minutes in the gastro-intestinal tract within the thorax and can be noted easily on portable radiograph of the chest (Fig. 1), thus confirming the diagnosis in the deeply cyanotic infant with a sometimes equivocal chest film.

During the brief interim before surgical correction, the head and chest of such infants should be raised 30 degrees and the baby placed on the side of the diaphragmatic defect in an effort to improve function of the contralateral lung. If the infant's condition deteriorates rapidly before operating facilities are available, an anaesthetist should administer oxygen by mask or through an endotracheal tube, assisting respirations gently, assiduously avoiding increases in positive pressure that might cause spontaneous rupture of a bleb on the lung. If no improvement results, emergency reduction of the viscera from the chest through a $10 \mathrm{~cm}$. divided rectus muscle incision may have to be carried out without waiting for more favourable circumstances. If cardiac arrest should occur, external compression of the thorax as described by Mathews, Avery, and Jude (1963) is most effective in managing this complication, once an adequate airway and supply of oxygen have been provided.

The intravenous administration of sodium bicarbonate or amine buffers (Tris, THAM) suggested by the studies of Kaplan (1962) and Kaplan, Fox, and

* Glaxo Laboratories, Ltd., Greenford, Middlesex, England. 
TABLE 1

DATA ON 27 SURGICAL CASES

\begin{tabular}{|c|c|c|c|c|c|c|c|}
\hline Case No. & $\begin{array}{c}\text { Age at } \\
\text { Operation } \\
\text { (hr.) }\end{array}$ & Viscera in Chest & Lung Aplasia & $\begin{array}{c}\text { Major } \\
\text { Assoc. } \\
\text { Anomaly }\end{array}$ & $\begin{array}{l}\text { Ladd's } \\
\text { Bands }\end{array}$ & $\begin{array}{c}\text { Gastros- } \\
\text { tomy }\end{array}$ & Post-operative Result \\
\hline & \multicolumn{7}{|c|}{ Divided Rectus Incision, Ventral Hernia (Group II) } \\
\hline $\begin{array}{r}1 \\
2 \\
3 \\
4 \\
5 \\
6 \\
7 \\
\\
8 \\
9 \\
10 \\
11\end{array}$ & $\begin{array}{r}6 \\
18 \\
9 \\
7 \\
6 \\
6 \\
12 \\
6 \\
\\
7 \\
15 \\
23 \\
4\end{array}$ & $\begin{array}{l}\text { GI, Sp, L } \\
\text { GI, Sp, L } \\
\text { GI } \\
\text { GI, Sp, S, L } \\
\text { GI, Sp } \\
\text { GI, Sp } \\
\text { GI, Sp, S } \\
\text { GI, Sp, S } \\
\text { GI, L } \\
\text { GI, Sp, L }\end{array}$ & $\begin{array}{c}\text { Agenesis } \\
0 \\
0 \\
0 \\
0 \\
\text { X-ray } \\
\text { Lt.-13 g. } \\
\text { Rt.-8 g. } \\
0 \\
0 \\
\text { Lt.-12 g. } \\
\text { Rt.-4 g. } \\
\text { X-ray }\end{array}$ & $\begin{array}{l}+ \\
0 \\
0 \\
0 \\
0 \\
+ \\
+ \\
\\
0 \\
0 \\
+ \\
0\end{array}$ & $\begin{array}{l}0 \\
+ \\
0 \\
+ \\
0 \\
+ \\
+ \\
+ \\
+ \\
+ \\
+ \\
+\end{array}$ & $\begin{array}{l}0 \\
+ \\
+ \\
+ \\
+ \\
+ \\
+ \\
+ \\
+ \\
+ \\
+\end{array}$ & $\begin{array}{c}\text { Died at } 3 \mathrm{hr} . \\
\text { Cured } \\
\text { Cured } \\
\text { Cured } \\
\text { Cured } \\
\text { Cured } \\
\text { Died at } 12 \mathrm{hr} \text {. } \\
\text { Cured } \\
\text { Cured } \\
\text { Died at } 18 \mathrm{hr} . \\
\text { Cured }\end{array}$ \\
\hline 11 & \multicolumn{7}{|c|}{ Paramedian Incision, Ventral Hernia (Group III) } \\
\hline \multirow[t]{2}{*}{$\begin{array}{l}12 \\
13 \\
14 \\
15 \\
16 \\
17\end{array}$} & $\begin{array}{r}12 \\
14 \\
12 \\
4 \\
10 \\
13\end{array}$ & $\begin{array}{l}\text { GI } \\
\text { GI, Sp, S } \\
\text { GI, Sp, S } \\
\text { GI, Sp, S } \\
\text { GI, Sp } \\
\text { GI, Sp, S }\end{array}$ & $\begin{array}{c}0 \\
0 \\
0 \\
0 \\
\text { Small bronchus } \\
\text { X-ray }\end{array}$ & $\begin{array}{l}\mathbf{0} \\
\mathbf{0} \\
\mathbf{0} \\
\mathbf{0} \\
\mathbf{0} \\
+\end{array}$ & $\begin{array}{l}0 \\
+ \\
0 \\
0 \\
0 \\
0\end{array}$ & $\begin{array}{l}0 \\
0 \\
0 \\
0 \\
+ \\
+\end{array}$ & $\begin{array}{c}\text { Cured } \\
\text { Cured } \\
\text { Died at } 1 \mathrm{hr} . \\
\text { Died at } 50 \mathrm{hr} \text {. } \\
\text { Died at } 12 \mathrm{hr} . \\
\text { Died at } 36 \mathrm{hr} .\end{array}$ \\
\hline & \multicolumn{7}{|c|}{ Primary Abdominal Wall Closure, No Hernia (Group IV) } \\
\hline $\begin{array}{l}18 \\
19 \\
20 \\
21 \\
22 \\
23 \\
24 \\
25 \\
26 \\
27\end{array}$ & $\begin{array}{r}8 \\
14 \\
10 \\
8 \\
13 \\
11 \\
4 \\
4 \\
15 \\
4 \\
7\end{array}$ & $\begin{array}{l}\text { GI, Sp, S } \\
\text { GI, Sp } \\
\text { GI, L } \\
\text { GI, Sp, S } \\
\text { GI, Sp, S } \\
\text { GI, Sp, S } \\
\text { GI, L } \\
\text { GI } \\
\text { GI, Sp } \\
\text { GI, Sp }\end{array}$ & $\begin{array}{c}0 \\
0 \\
\text { Rt.-12 } \mathrm{g} . \\
\text { Lt. }-12 \mathrm{~g} . \\
\text { Lt. }-14 \mathrm{~g} . \\
0 \\
0 \\
\text { Lt. }-13 \mathrm{~g} . \\
0 \\
0\end{array}$ & $\begin{array}{l}0 \\
0 \\
0 \\
0 \\
0 \\
0 \\
0 \\
+ \\
0 \\
0\end{array}$ & $\begin{array}{l}0 \\
0 \\
+ \\
0 \\
0 \\
+ \\
+ \\
0 \\
+ \\
+\end{array}$ & $\begin{array}{l}0 \\
0 \\
+ \\
0 \\
0 \\
0 \\
+ \\
0 \\
0 \\
0\end{array}$ & $\begin{array}{l}\text { Died at } 40 \mathrm{hr} \text {. } \\
\text { Died at } 50 \mathrm{hr} \text {. } \\
\text { Died at } 1 \mathrm{hr} \text {. } \\
\text { Died at } 60 \mathrm{hr} \text {. } \\
\text { Died at } 36 \mathrm{hr} \text {. } \\
\text { Died at } 3 \mathrm{hr} \text {. } \\
\text { Died at } 36 \mathrm{hr} \text {. } \\
\text { Died at } 24 \mathrm{hr} \text {. } \\
\text { Lived } \\
\text { Died at } 17 \mathrm{hr} \text {. }\end{array}$ \\
\hline
\end{tabular}

$\mathrm{GI}=$ small bowel and colon; $\mathrm{Sp}=$ spleen; $\mathrm{S}=$ stomach; $\mathbf{L}=$ liver $; \mathbf{g} .=$ gram.

Clark (1962) to correct a low blood $p \mathrm{H}$ at the time of admission, should be deferred until assisted respiration has been given an adequate opportunity to reduce the $\mathrm{PCO}_{2}$. Sodium bicarbonate, though initially helpful in raising a low blood $p \mathrm{H}$, may subsequently contribute to a rise in the $\mathrm{PCO}_{2}$ and deepening of the acidosis as in Cases 15 and 16 (Table 1). For this reason amine buffers are preferred when available.

\section{Surgical Considerations}

Most surgeons agree that the abdominal surgical approach advocated originally by Ladd and Gross (1940) is far more satisfactory than the thoracic approach for correction of these defects. With the thoracic approach, malrotation of the small intestine and partial obstruction of the duodenum by bands, -which occurs in slightly more than $50 \%$ of the cases (Table 1) - cannot be visualized. Reducing the viscera into the diminutive abdominal cavity is often extremely difficult; according to Potts, it is 'akin to forcing spaghetti into a soda pop bottle', and may result in a marked increase in intra-abdominal tension which cannot be relieved simply by creation of an incisional hernia at the time of abdominal wound closure.

In the authors' experience, a $10 \mathrm{~cm}$. long abdominal incision as depicted in Fig. $2 \mathrm{a}$, completely dividing the ipsilateral rectus muscle, should be utilized rather than a paramedian incision (Fig. 2b) for the following reasons: (1) a $10 \mathrm{~cm}$. divided rectus muscle incision permits construction of the most capacious ventral hernia in such newborn, (2) the gaping rectus muscle does not limit the hernia size and promotes free effective excursions of the diaphragm, i.e. more normal infant abdominal respiration after operation, (3) it provides optimal exposure of the diaphragmatic defect and facilitates closure of particularly large diaphragmatic defects by an 'overhead-sliding-door' technique (Meeker, to be published).

Once repair of the diaphragmatic defect has been accomplished, a chest tube should be inserted through the corner of the diaphragmatic closure, brought out through the corner of the abdominal wound and attached to water-seal drainage. Subsequently examination for Ladd's bands and their division 


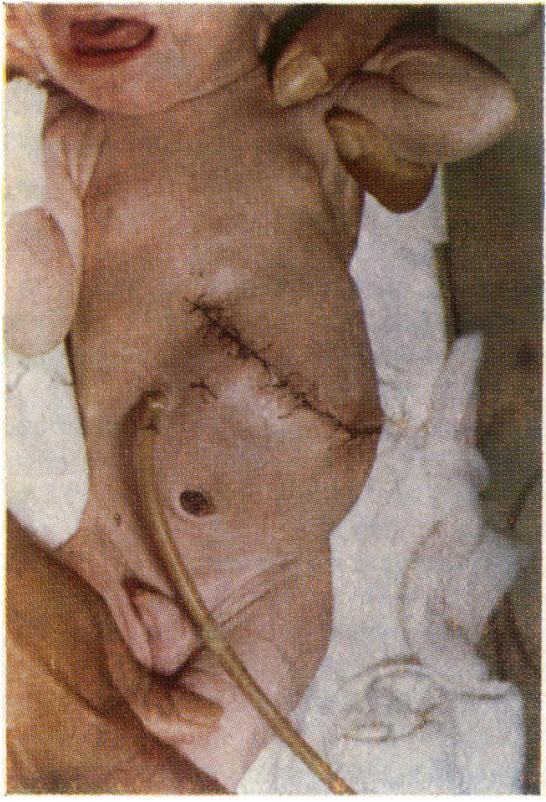

FIG. 2a.-Case 11, 10th day. Note the left $10 \mathrm{~cm}$. divided rectus ventral hernia still filled to capacity, precluding primary abdominal wound closure.

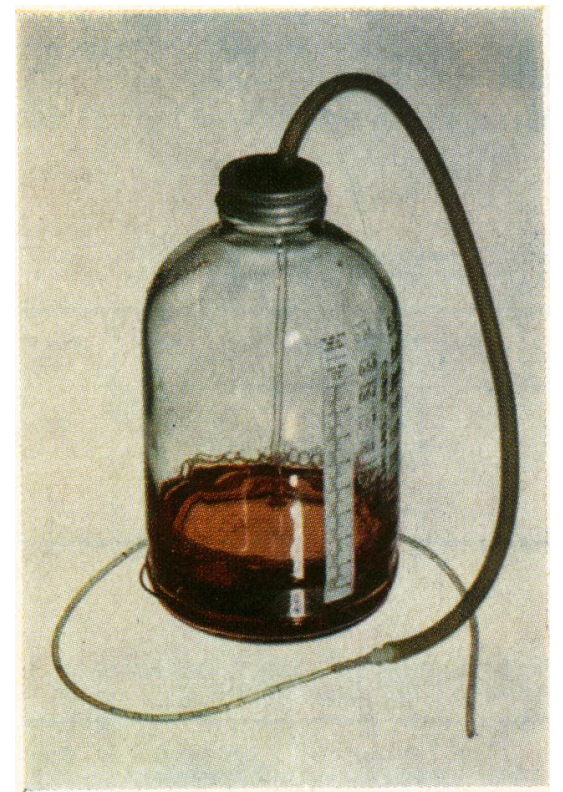

FIG. 2c.-A photograph of a $1,000 \mathrm{ml}$. parenteral fluid flask adapted for water-seal chest drainage. Note there is only $1-2 \mathrm{~cm}$. of fluid in the bottle so that water-seal of the chest is insured, yet the level of fluid is sufficiently low so that any appreciable increase in positive pressure following a spontaneous pneumothorax can be decompressed and will 'bubble out'.

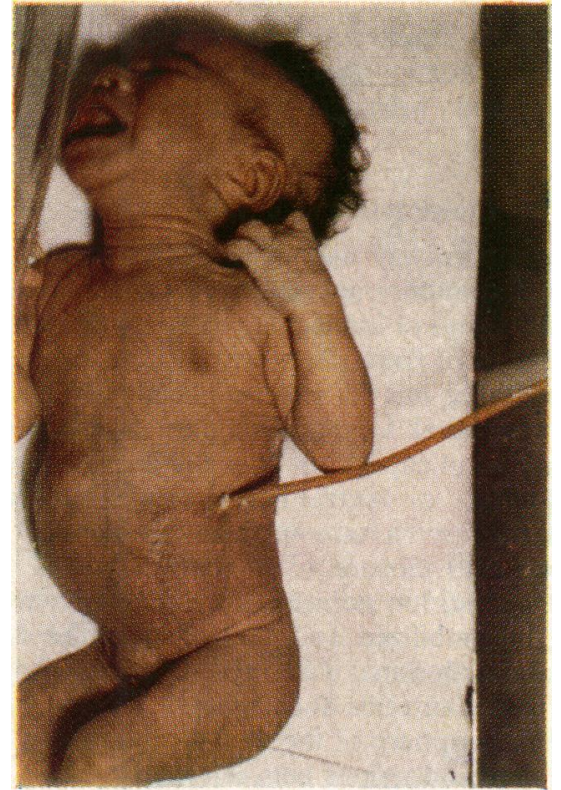

FIG. 2b.-A 2-week old infant following surgical correction of a massive eventration of the right diaphragm, gastrostomy, and construction of two intentional skin-covered ventral hernia, i.e. right $10 \mathrm{~cm}$. divided rectus, and left paramedian incision. Note the divided rectus incisional hernia is full and bulging and the paramedian incisional hernia flat and empty.

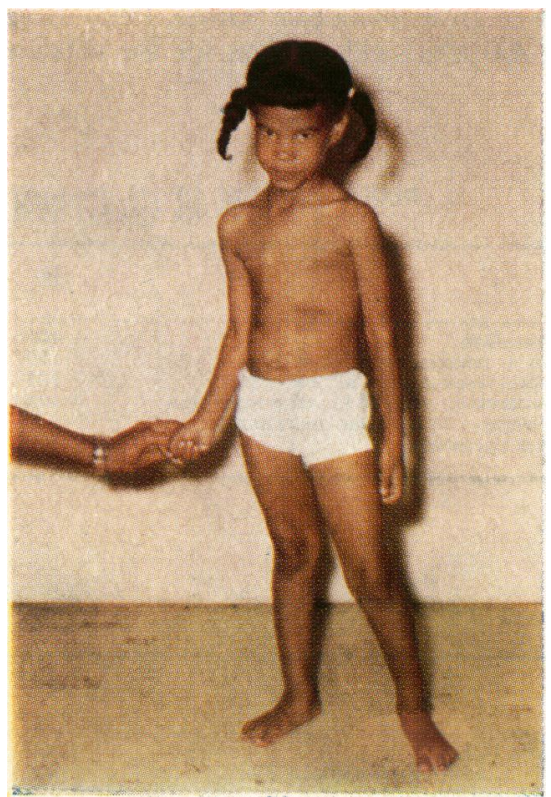

Fig. 2d.-A photograph of the same child as Fig. $2 b$ at 5 years of age showing that the $10 \mathrm{~cm}$. divided rectus ventral hernia had undergone spontaneous closure and the paramedian incision had healed well. 
should be carried out, followed by establishment of a gastrostomy (Meeker and Snyder, 1962a). Finally the divided rectus ventral hernia should be constructed and primary abdominal wall closure deferred.

\section{Construction of Ventral Hernia}

In approximately half of the cases in this study (Group II) the abdominal cavity was underdeveloped, diminutive, and of inadequate capacity to accept the viscera reduced from the thorax. Thus the surgeon had no choice but to undermine the subcutaneous tissue peripheral to the cut edges of the incision (preferably not superiorly over the thorax) to create a 'skin pouch' or ventral hernia of sufficient size to contain the viscera reduced from the thorax.

Before skin closure of a ventral hernia, if the patient's condition permits, the parietal peritoneum should be mobilized and sutured over the divided rectus and abdominal wall musculature and approximated to the anterior abdominal wall fascia around the entire periphery of the wound, to reduce formation of dense adhesions between the cut edges of the muscle and herniating loops of bowel. Thus a 'peritonealized surface' may be created up to the level of the subcutaneous tissue (Meeker and Snyder, 1962b). Drugs, to be effective, should be given parenterally during the first 3 days after operation. The skin edges alone are approximated as in a skin closure of an omphalocele (Gross, 1953) using interrupted 4-0 black silk sutures for the subcutaneous fascia and interrupted 5-0 black silk vertical mattress sutures for apposition of the skin edges. Particular attention is needed not to pierce the bowel loops that are lying directly below the surface of the skin.

Not infrequently ( 10 cases, Group IV) the capacity of the abdominal cavity may seem adequate to accommodate the reduced abdominal viscera, particularly when there is little air in the gastrointestinal tract, without undue increases in intraabdominal tension, and it becomes readily apparent that primary abdominal wall closure can be accomplished. The temptation to close the wound primarily in such infants less than 1 day of age, even when deceptively easy, should be resisted, and empirically a skin closure alone done and primary wound closure deferred. This clinical situation, where primary wound closure could be and was accomplished with ease, was encountered by experienced surgeons in 3 (Cases 24, 25, and 27) out of 10 patients in Group IV, and each of the infants died within 36 hours following apparently uneventful, successful correction of their diaphragmatic defects. In contrast the favourable outcome and clinical course of 2 (Cases 11 and 5 in Group II) with a $10 \mathrm{~cm}$. divided rectus ventral hernia are documented by the blood-gas studies in Table 2 and Table 3, respectively. It should be added that haste to shorten the anaesthesia and operating time may be less of a virtue than a hazard since, within reason, prolonged gentle assisted respirations benefit these infants very materially. Although significant numbers of survivors have been

TABLE 2

BLOOD STUDIES OF $p \mathrm{H}$, PCa, 2 AND BASE EXCESS AFTER OPERATION IN CASE 11 SHOWING MIXED ACIDOSIS WITH RESPIRATORY DEPRESSION

\begin{tabular}{|c|c|c|c|c|c|}
\hline & $p \mathbf{H}$ & $\underset{(\mathrm{mm} . \mathrm{Hg})}{\mathrm{PCO}_{2}}$ & $\underset{(\mathrm{mEq} / \mathrm{l} .)}{\text { Base Excess }}$ & $\begin{array}{l}\text { Left Lung } \\
\text { Expansion }\end{array}$ & $\begin{array}{c}\text { Respiratory } \\
\text { Rate }\end{array}$ \\
\hline $\begin{array}{l}\text { Before operation } \\
\text { Operation + assisted respiration } 2 \mathrm{hr} . \\
\text { Spontaneous respiration } 6 \mathrm{hr} \text {. post-op. } \\
\text { Spontaneous respiration } 18 \mathrm{hr} \text {. after operation } \\
\text { Tracheal suction } 24 \mathrm{hr} \text {. after operation } \\
48 \mathrm{hr} \text {. after operation } \ldots . \\
\end{array}$ & $\begin{array}{l}6 \cdot 990 \\
7 \cdot 110 \\
7 \cdot 145 \\
7 \cdot 198 \\
7 \cdot 330 \\
7 \cdot 320\end{array}$ & $\begin{array}{r}105 \cdot 2 \\
70 \cdot 4 \\
41 \cdot 0 \\
55 \cdot 0 \\
38 \cdot 0 \\
41 \cdot 5\end{array}$ & $\begin{array}{l}-20 \cdot 5 \\
-13 \cdot 2 \\
-13 \cdot 6 \\
-8 \cdot 5 \\
-4 \cdot 4 \\
-4 \cdot 0\end{array}$ & $\begin{array}{c}0 \\
0 \\
20 \% \\
75 \% \\
90 \% \\
100 \%\end{array}$ & $\begin{array}{c}52 \\
72 \text { spont. } \\
120 \\
90 \\
110 \\
70\end{array}$ \\
\hline
\end{tabular}

TABLE 3

BLOOD STUDIES OF $p \mathrm{H}$, PCO2, AND BASE EXCESS AFTER OPERATION IN CASE 5 , SHOWING MIXED ACIDOSIS WITH $\mathrm{CO}_{2}$ NARCOSIS AND RESPIRATORY DEPRESSION

\begin{tabular}{|c|c|c|c|c|c|}
\hline & $p \mathbf{H}$ & $\underset{(\mathrm{mm} . \mathrm{Hg})}{\mathrm{PCO}_{2}}$ & $\underset{(\mathrm{mEq} / \mathrm{l} .)}{\text { Base Excess }}$ & $\begin{array}{l}\text { Left Lung } \\
\text { Expansion }\end{array}$ & $\underset{\text { Rate }}{\text { Respiratory }}$ \\
\hline 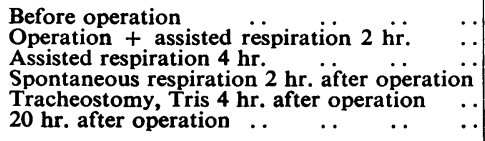 & $\begin{array}{l}6 \cdot 900 \\
6 \cdot 960 \\
7 \cdot 125 \\
6 \cdot 910 \\
7 \cdot 105 \\
7 \cdot 228\end{array}$ & $\begin{array}{r}112 \cdot 0 \\
95 \cdot 0 \\
57 \cdot 5 \\
110 \cdot 0 \\
69 \cdot 0 \\
33 \cdot 5\end{array}$ & $\begin{array}{l}-13 \cdot 6 \\
-11 \cdot 0 \\
-13 \cdot 0 \\
-20 \cdot 8 \\
-14 \cdot 0 \\
-12 \cdot 5\end{array}$ & $\begin{array}{l}0 \\
0 \\
0 \\
50 \% \\
70 \% \\
80 \%\end{array}$ & $\begin{array}{l}48 \\
50 \text { spont. } \\
65 \text { spont. } \\
44 \\
66 \\
85\end{array}$ \\
\hline
\end{tabular}


reported (Cerilli, 1964) following correction of a diaphragmatic defect and primary abdominal wall closure in infants less than 24 hours after birth, the over-all mortality has approached $50 \%$.

\section{Post-operative Management}

Clinical Appraisal of Status. In the first 48 hours after operation, expansion of the lung, the respiratory rate, and the state of alertness and responsiveness of the infant are the most significant clinical guides, and reflect changes in the blood-gas levels which are of greatest therapeutic significance.

During this period serial portable chest radiographs showed that in 14 of the 27 surgical cases 50 to $75 \%$ expansion of the lung occurred on water-seal drainage in the first 48 hours following operation. If this does not occur, hypoplasia of the lung should be suspected.

If during the first 48 hours after operation the respiratory rate falls to 40 to 50 breaths a minute regardless of the expansion of the lung, it should be interpreted not as a favourable sign but an ominous one portending or representing a falling blood $p \mathrm{H}$ and incipient respiratory depression due to a rising blood $\mathrm{PCO}_{2}$. Concomitant development of lethargy and the need to stimulate the baby to breathe generally indicates $\mathrm{CO}_{2}$ narcosis. Cyanosis often develops slowly, almost imperceptibly, and is a late or the last feature of the clinical picture which changes insidiously. This clinical situation, when coupled with cyanosis and irregular respirations, initially suggests strongly that some major central nervous system catastrophe has occurred. However, it can be differentiated from a central nervous system abnormality by noting that the pupils are equal and react to light; and the child, on vigorous stimulation, can be roused momentarily to react and manifest reflexes like a normal newborn infant with an intact normal central nervous system.

To be safe, one should anticipate and suspect a transient fall in the blood $p \mathrm{H}$ and a rise in the $\mathrm{PCO}_{2}$ in the first 24 to 36 hours after operation. Regardless of the apparently favourable clinical course of the patient and whenever possible, appropriate blood-gas studies should be performed at least every 12 hours, in order to anticipate the need for additional therapy.

During the first 36 hours after operation, when well-documented evidence of falling blood $p \mathrm{H}$ and rising $\mathrm{PCO}_{2}$ are obtained, tracheostomy and gentle manually assisted respirations, and the administration of amine buffers may have to be considered. Fortunately this is rarely necessary when a $10 \mathrm{~cm}$. divided rectus incision and ventral hernia has been employed (in this series only Case 5, Table 1).
Management of 'Shallow' Water-seal Chest Drainage. 'Shallow' water-seal chest drainage employing preferably a Baxter K-61 plastic catheter is the safest and most effective method of gradually removing air and fluid from the infant's chest, yet protecting against a spontaneous tension pneumothorax. Creation of a vacuum, or suction on the chest catheter, should be avoided assiduously and supplanted effectively by water seal only.

A plastic catheter is ideal for 'shallow' water-seal chest drainage in these particular infants because it has a relatively larger lumen than does a comparable rubber catheter and because it rarely becomes plugged with blood clots. This latter fact is particularly important because shallow water-seal chest drainage, only 1 to $2 \mathrm{~cm}$. of fluid in the bottle, protects against the sudden development of a spontaneous pneumothorax by permitting immediate 'blow off' of accumulated air (Fig. 2c).

At first the column of water in the tube in the water-seal bottle fluctuates with each breath. When fluctuation ceases after the first day or two, the lung is usually expanded and this can be confirmed radiologically. If bubbles appear continuously in the water-seal bottle, a spontaneous tension pneumothorax has developed, but this will seal itself as a rule without resorting to chest suction which promotes air leakage and is usually contraindicated. Of the 27 surgical patients, 20 had chest drainage with water seal: 2 (Cases 14 and 20) of the remaining 7 without chest drainage died immediately after operation from spontaneous tension pneumothorax.

Management of Gastrostomy. Gastrostomy is an important adjunct in preventing vomiting with pulmonary aspiration, particularly in cases where malrotation with duodenal obstruction has been corrected. It was employed in 9 out of 11 cases in Group II, 2 of 6 cases in Group III, and 2 of 10 cases in Group IV. A further advantage of gastrostomy in such infants is that air normally swallowed by a crying baby is vented continuously through an open gastrostomy tube (Meeker and Snyder, 1962a), preventing distension of the intestinal tract. In conjunction with ventral hernia, it reduces to a minimum post-operative intra-abdominal tension and the space required by the loops of intestine, distended with air, that have been returned to the abdomen.

Though effective in this latter regard, in no case to date has gastrostomy resulted in a noticeable reduction in the size of the ventral hernia in the immediate post-operative period (Fig. 2a) sufficient to permit primary closure of the abdominal wall in the first two weeks of life. 
Management of Ventral Hernia. Generally, growth or increase in the capacity of the abdominal cavity occurs slowly and the ventral hernia may be needed and filled to capacity, as shown in Fig. 2a, during the first days and weeks following correction of the diaphragmatic defect. The necessary delay in closure permits the abdominal cavity to enlarge and the fascial defect to become progressively smaller with diminution in the size of the ventral hernia. Complete closure occurred spontaneously in one patient, as shown in Fig. 2d. Mothers report that the ventral hernia is small or empty in the morning before the child has been fed and that the abdominal contour is relatively normal. In this study, closure of the fascia and rectus muscle to correct the ventral hernia (Group II cases) during the neonatal period has had to be deferred, but has been carried out electively at 1 to 3 years of age when no further spontaneous closure of the fascial defect is noted.

Dense adhesions will form as a result of construction of a temporary ventral hernia, and it must be recognized that families of such patients have had time to know and love their child, which makes ventral herniorrhaphy after the neonatal period a most formidable surgical undertaking.

Ventral herniorrhaphy should be preceeded by effective gastro-intestinal suction 24 hours before operation. There have been no deaths in any case in this study (Group II or III, Table 1) following ventral herniorrhaphy, but the calculated risk of repair and the inherent disadvantages of a ventral hernia are acknowledged and accepted because of what is believed to be its life-saving importance following repair of diaphragmatic defects in infants during the first 24 hours of life.

\section{Results in Surgical Cases}

During the period of this study, 1957 to 1963 , as shown in Table 1, 10 infants (Group IV) had surgical repair of a diaphragmatic defect with primary closure of all layers of the abdominal wall, and there was only one survivor. Aplasia of the lung was documented in 4 (Cases 20, 21, 22, and 25) and each infant died. One major associated anomaly was noted in one child (Case 25) who developed hyaline membrane disease.

Diaphragmatic defects in 6 infants (Group III) were corrected by the standard technique employing a paramedian incision and creating a ventral hernia, and 2 survived. Aplasia of the lung was described in 2 in this group (Cases 16 and 17) and both patients died. There was one major associated anomaly (Case 17) with congenital heart disease and one death (Case 14) that might have been averted by water-seal chest drainage.
Finally in 11 entirely comparable, unselected infants (Group II) a $10 \mathrm{~cm}$. divided rectus muscle incision was employed and only a skin-covered ventral hernia was constructed. There were 8 survivors in this group, and significantly 2 (Cases 6 and 11) subsequently manifested aplasia of the ipsilateral lung on chest film. There were 3 deaths, 2 (Cases 7 and 10) occurring in children moribund with irreversible central nervous system damage due to anoxia before operation, and the third (Case 1) who had absence of the diaphragm and ipsilateral lung. There were 4 instances of aplasia of the lung in the entire group and 4 instances of a major associated congenital anomaly.

\section{Conclusions}

The lower mortality in Group II suggests that reducing intra-abdominal tension by creating an intentional ventral hernia, utilizing a $10 \mathrm{~cm}$. incision that divides the rectus musculature, is of real benefit and is preferred to a paramedian approach because of the greater capacity of the ventral hernia. Gastrostomy is also a valuable adjunct.

The decision to create a temporary ventral hernia should be made primarily on the basis of the infant's age and not on clinical appraisal of the infant's condition and the adequacy of the capacity of the abdominal cavity.

A separate study made by the authors of full-term and premature infants with diaphragmatic defects between 2 and 7 days of age (not included in this report) indicates that creation of an intentional ventral hernia may be extremely valuable in this group also. A further study of 33 cases with diaphragmatic defects, repaired after the age of 1 week, showed that there were only 2 deaths following surgical correction of the defect and in no instance was a ventral hernia created, so that in older children who represent the 'survival of the fittest' temporary ventral hernia has little to offer.

Procrastination regarding surgical repair in infants under 1 day of age is to be condemned, since without prompt surgical intervention, relatively few such infants will survive the first day of life (Butler and Claireaux, 1962).

\section{Summary}

Increasing the capacity of the abdomen by creating a $10 \mathrm{~cm}$. divided rectus ventral hernia, after repair of a diaphragmatic defect in infants during the first day of life, improves ventilation and leads to early correction of the respiratory and circulatory disturbances present. Reduction of abdominal viscera from the 
thorax to an underdeveloped, diminutive abdominal cavity, followed by primary abdominal wall closure, increases intra-abdominal tension, limits excursion of the diaphragm, and compresses the inferior vena cava.

The resulting respiratory, circulatory, and physiological derangements consist of severe acidosis, $\mathrm{CO}_{2}$-retention, respiratory depression from $\mathrm{CO}_{2}$ narcosis, and tissue anoxia.

The ventral hernia created can be corrected most appropriately at the time when the abdominal cavity has enlarged sufficiently to accommodate all the abdominal viscera without undue tension.

The authors wish to acknowledge their indebtedness to Dr. Frederick Leix, Chief of the Pediatric Surgical Service, Los Angeles County Hospital, and his staff for many contributions and co-operation in this study.

\section{REFERENCES}

Bonham Carter, R. E., Waterston, D. J., and Aberdeen, E. (1962) Hernia and eventration of the diaphragm in childhood. Lancet, $1,656$.

Butler, N., and Claireaux, A. E. (1962). Congenital diaphragmatic hernia as a cause of perinatal mortality. ibid., 1, 659.

Cerilli, G. J. (1964). Foramen of Bochdalek hernia: a review of the experience at Children's Hospital of Denver, Colorado. Ann. Surg., 159, 385.

Gross, R. E. (1953). The Surgery of Infancy and Childhood. Saunders, Philadelphia.

Kaplan, S. A. (1962). Tris (hydroxymethyl) aminomethane (THAM) -a new buffer for therapeutic use Amer. $J$. Dis. Child., 103, 1.

-, Fox, R. P., and Clark, L. C., Jr. (1962). Amine buffers in the management of acidosis: study of respiratory and mixed acidosis. ibid., $103,4$.

Ladd, W. E., and Gross, R. E. (1940). Congenital diaphragmatic hernia. New Engl. J. Med., 223, 922.

Mathews D. H., Avery, M. E., and Jude, J. R. (1963). Closed-chest cardiac massage in the newborn infant. J. Amer. med. Ass., 183, 964.

Meeker, I. A., and Snyder, W. H. (1962a). Gastrostomy for the newborn surgical patient. A report of 140 cases. Arch. Dis. Childh., 37, 159.

_, and - (1962b). Surgical management of diaphragmatic defects in the newborn infant. Amer. J. Surg., 104, 196. 